\title{
Bioimpedance Vector References Need to Be Period-Specific for Assessing Body Composition and Cellular Health in Elite Soccer Players: A Brief Report
}

\author{
Tindaro Bongiovanni ${ }^{1,2}$, Gabriele Mascherini ${ }^{3, *(\mathbb{D})}$, Federico Genovesi ${ }^{4}$, Giulio Pasta ${ }^{5}$, \\ Fedon Marcello Iaia ${ }^{2}$, Athos Trecroci ${ }^{2}{ }^{\mathbb{D}}$, Marco Ventimiglia ${ }^{6}$, Giampietro Alberti ${ }^{2}$ \\ and Francesco Campa ${ }^{7}$ (D) \\ 1 Department of Health, Performance and Recovery, Parma Calcio 1913, 40121 Parma, Italy; \\ tindaro.bongiovanni@gmail.com \\ 2 Department of Biomedical Sciences for Health, Università degli Studi di Milano, 20129 Milano, Italy; \\ marcello.iaia@unimi.it (F.M.I.); Athos.Trecroci@unimi.it (A.T.); gianpietro.alberti@unimi.it (G.A.) \\ 3 Department of Experimental and Clinical Medicine, Università degli Studi di Firenze, 50139 Florence, Italy \\ 4 Medical Department Manchester City Football Club, Manchester 03101, UK; fede.genovesi@libero.it \\ 5 Medical Department Parma Calcio 1913, 40121 Parma, Italy; ghitopasta@hotmail.com \\ 6 Inflammatory Bowel Disease Unit, A.O.O.R. Villa Sofia-Cervello, 90146 Palermo, Italy; \\ marco.ventimiglia@unipa.it \\ 7 Department for Life Quality Studies, University of Bologna, 47921 Rimini, Italy; francesco.campa3@unibo.it \\ * Correspondence: gabriele.mascherini@unifi.it
}

Received: 27 August 2020; Accepted: 29 September 2020; Published: 1 October 2020

check for updates

\begin{abstract}
Purpose: Bioimpedance data through bioimpedance vector analysis (BIVA) is used to evaluate cellular function and body fluid content. This study aimed to (i) identify whether BIVA patters differ according to the competitive period and (ii) provide specific references for assessing bioelectric properties at the start of the season in male elite soccer players. Methods: The study included 131 male soccer players (age: $25.1 \pm 4.7 \mathrm{yr}$, height: $183.4 \pm 6.1 \mathrm{~cm}$, weight: $79.3 \pm 6.6$ ) registered in the first Italian soccer division (Serie A). Bioimpedance analysis was performed just before the start of the competitive season and BIVA was applied. In order to verify the need for period-specific references, bioelectrical values measured at the start of the season were compared to the reference values for the male elite soccer player population. Results: The results of the two-sample Hotelling $\mathrm{T}^{2}$ tests showed that in the bivariate interpretation of the raw bioimpedance parameters (resistance $(\mathrm{R})$ and reactance $\left(\mathrm{XC}_{\mathrm{c}}\right)$ ) the bioelectric properties significantly $\left(\mathrm{T}^{2}=15.3, \mathrm{~F}=7.6, p \leq 0.001\right.$, Mahalanobis $\mathrm{D}=0.45$ ) differ between the two phases of the competition analyzed. In particular, the mean impedance vector is more displaced to the left into the R-Xc graph at the beginning of the season than in the first half of the championship. Conclusions: For an accurate evaluation of body composition and cellular health, the tolerance ellipses displayed by BIVA approach into the R-Xc graph must be period-specific. This study provides new specific tolerance ellipses (R/H: $246 \pm 32.1$,

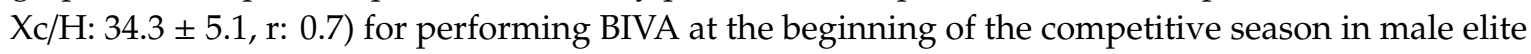
soccer players.
\end{abstract}

Keywords: BIVA; phase angle; R-Xc graph; tolerance ellipses

\section{Introduction}

Body composition analysis is currently one of the most studied evaluations in sport, mainly for the relationship between physical characteristics and sports performance [1]. In sports, excess fat mass reduces endurance performance, while an increase in lean mass, especially muscle mass, is associated 
with an increase in power and strength [2]. Furthermore, the assessment of localized body composition allows the identification of differences in muscle mass and strength between areas of the body and may allow a reduction in the risk of injury (evaluation of contralateral limbs, agonist-antagonists) [3].

Body composition assessment should also be considered in sports involving weight categories, where athletes benefit from being placed in a lower weight category, in these cases any weight loss must therefore be monitored closely. Excessive training coupled with calorie restrictions can lead to excessive, unnecessary and dangerous weight loss. This weight loss in both women and men decreases performance, bone mineral density, muscle mass and is detrimental to health $[4,5]$.

Bioelectrical impedance vector analysis (BIVA) is a method widely used to evaluate body composition and cellular health in athletes, as well as in the general population [6-9]. This method considers the raw bioelectrical parameters (resistance and reactance) standardized for the height of the subjects as a vector within a graph. Resistance $(R)$ is the opposition to the flow of an injected alternating current, at any current frequency, through intra- and extra-cellular ionic solutions, while reactance $\left(X_{c}\right)$ represents the dielectric or capacitive component of cell membranes and organelles, and tissue interfaces [10].

BIVA allows for the monitoring of vector changes over time or the comparison of the vector position within the R-Xc graph on specific population tolerance ellipses [11-13]. Given the ease and repeatability of this method, several references for athletes have recently been proposed, including those for soccer players [14], volleyball players [15], and cyclists [16], while also considering the competitive level of the athlete.

In soccer, Levi Micheli et al. [14] were the first to demonstrate how athletes need to be assessed on specific tolerance ellipses, showing bioelectric values that were far different than those of the normal healthy population. Subsequently, Mascherini et al. [17] suggested how bioimpedance vectors show displacements over the season, reflecting the changes that occur in the body composition and physical condition of the players. This was later confirmed by Campa et al. [18] who analyzed the bioelectrical changes comparing BIVA to results obtained by Dual X-ray Absorptiometry (DXA) and dilution techniques over a season in athletes, also showing that these vector changes occur in many other sports.

During the different phases of competition, the one which precedes the start of the season is among the most important periods in which to evaluate the athlete's physical condition and the body composition adjustments that are sought during the pre-season. Considering the vector changes that occur over the season, the bioelectrical references used in the BIVA assessment must be specific for the competitive period in which the athlete is tested. Therefore, the purpose of this study was to show how BIVA references provided in different phases of the season differ in male elite soccer players, also providing new references for assessing body composition in the start-of-the season period.

\section{Materials and Methods}

\subsection{Design and Participants}

A total of 131 male professional soccer players (age: $25.1 \pm 4.7 \mathrm{yr}$; height: $183.4 \pm 6.1 \mathrm{~cm}$; weight: $79.3 \pm 6.6 \mathrm{Kg}$ ) were recruited and participated in this observational study.

The inclusion criteria were: (1) players registered and participating in the first (Serie A) Italian National division; (2) non-injured at the time of the assessment. After having been informed about the aims and the procedures of the research, all athletes gave their written informed consent. The project was approved by the Bioethics Committee of the University of Milan (approval code: 1052019) and was conducted in accordance with the guidelines of the declaration of Helsinki.

\subsection{Procedures}

All measurements were performed in resting and fasting conditions at the facilities of the teams in the last week of August at 8.30 a.m. Generally, this period corresponds to the end of the preparation for 
the competitive season; therefore, it coincides with the start of the season. Body height was recorded to the nearest $0.1 \mathrm{~cm}$ with a stadiometer (SECA ${ }^{\circledR} 240$, Hamburg, Germany) and weight was measured to the nearest $0.1 \mathrm{Kg}$ with a calibrated weight scales (SECA ${ }^{\circledR}$ 877, Hamburg, Germany).

Whole-body impedance was obtained using a bioimpedance analyzer (BIA 101 Anniversary Edition, Akern, Florence, Italy). The device emits an alternating sinusoidal electric current of $400 \mathrm{~mA}$ at an operating single frequency of $50 \mathrm{kHz}( \pm 0.1 \%)$. Subjects were positioned with a leg opening of $45^{\circ}$ with respect to the midline of the body, and with the upper limbs positioned $30^{\circ}$ away from the trunk. The bioelectric phase angle (PhA) was calculated as the arctangent of $X_{c} / R \times 180 / \pi$. BIVA was carried out using the classic methods, e.g., normalizing R (ohm) and $X_{c}(\mathrm{ohm})$ for height in meters $[6,8]$.

\subsection{Statistical Analyses}

The two-sample Hotelling $\mathrm{T}^{2}$ test was used to compare the differences in the mean impedance vectors between the bioimpedance data measured on the athletes of this study and the reference bioelectric values proposed by Levi Micheli et al. [14] The 50, 75, and 95\% tolerance ellipses were generated using the BIVA software [19]. Statistical significance was predetermined as $p<0.05$. Data were analyzed with IBM SPSS Statistics, version 24.0 (IBM Corp., Armonk, NY, USA).

\section{Results}

Table 1 shows anthropometric and bioelectrical characteristics of the soccer player.

Table 1. Descriptive statistics for the soccer players according to playing position.

\begin{tabular}{cccccc}
\hline Variable & $\begin{array}{c}\text { Goalkeepers } \\
\boldsymbol{n = ( 1 5 )}\end{array}$ & $\begin{array}{c}\text { Defenders } \\
\boldsymbol{n = ( 3 8 )}\end{array}$ & $\begin{array}{c}\text { Midfielders } \\
\boldsymbol{n = ( 3 8 )}\end{array}$ & $\begin{array}{c}\text { Forwards } \\
\boldsymbol{n = ( 4 0 )}\end{array}$ & $\begin{array}{c}\text { All } \\
\boldsymbol{n}=\mathbf{( 1 3 1 )}\end{array}$ \\
\hline Age (years) & $24.2 \pm 5.9$ & $26.6 \pm 4.8$ & $25.0 \pm 4.8$ & $24.5 \pm 3.9$ & $25.1 \pm 4.7$ \\
Weight $(\mathrm{kg})$ & $86.7 \pm 5.4$ & $80.6 \pm 5.6$ & $76.8 \pm 5.6$ & $77.6 \pm 6.5$ & $79.3 \pm 6.6$ \\
Height $(\mathrm{cm})$ & $188.3 \pm 3.5$ & $185.1 \pm 5.0$ & $181.4 \pm 5.2$ & $181.8 \pm 7.2$ & $181.8 \pm 7.2$ \\
$\mathrm{BMI}\left(\mathrm{kg} / \mathrm{m}^{2}\right)$ & $24.5 \pm 1.0$ & $23.5 \pm 0.8$ & $23.3 \pm 1.0$ & $23.5 \pm 1.0$ & $23.5 \pm 1.0$ \\
$\mathrm{R} / \mathrm{H}(\mathrm{ohm} / \mathrm{m})$ & $234.0 \pm 18.1$ & $242.9 \pm 17.0$ & $251.9 \pm 18.9$ & $254.6 \pm 21.9$ & $248.1 \pm 20.3$ \\
$\mathrm{Xc} / \mathrm{H}(\mathrm{ohm} / \mathrm{m})$ & $33.0 \pm 3.9$ & $34.4 \pm 3.1$ & $34.7 \pm 3.2$ & $35.4 \pm 3.0$ & $34.6 \pm 3.3$ \\
$\mathrm{PhA}($ degree $)$ & $8.0 \pm 0.7$ & $8.1 \pm 0.5$ & $7.8 \pm 0.4$ & $7.9 \pm 0.4$ & $8.0 \pm 0.5$ \\
\hline
\end{tabular}

Abbreviations: BMI, body mass index; $\mathrm{R} / \mathrm{H}$, resistance standardized for height; $\mathrm{Xc} / \mathrm{H}$, reactance standardized for height; $\mathrm{PhA}$, phase angle.

The results of the two-sample Hotelling's $\mathrm{T}^{2}$ test showed separate $95 \%$ confidence ellipses indicating a significant difference $\left(\mathrm{T}^{2}=15.3, \mathrm{~F}=7.6, p \leq 0.001\right.$, Mahalanobis $\left.\mathrm{D}=0.45\right)$ between the BIVA patters measured in this study and those proposed by Levi Micheli et al. [14] as a reference for the male elite soccer players population (Figure 1a).

The new reference ellipses and the single bioimpedance vectors measured in the soccer players at the start of the season are shown in Figure 1b. 

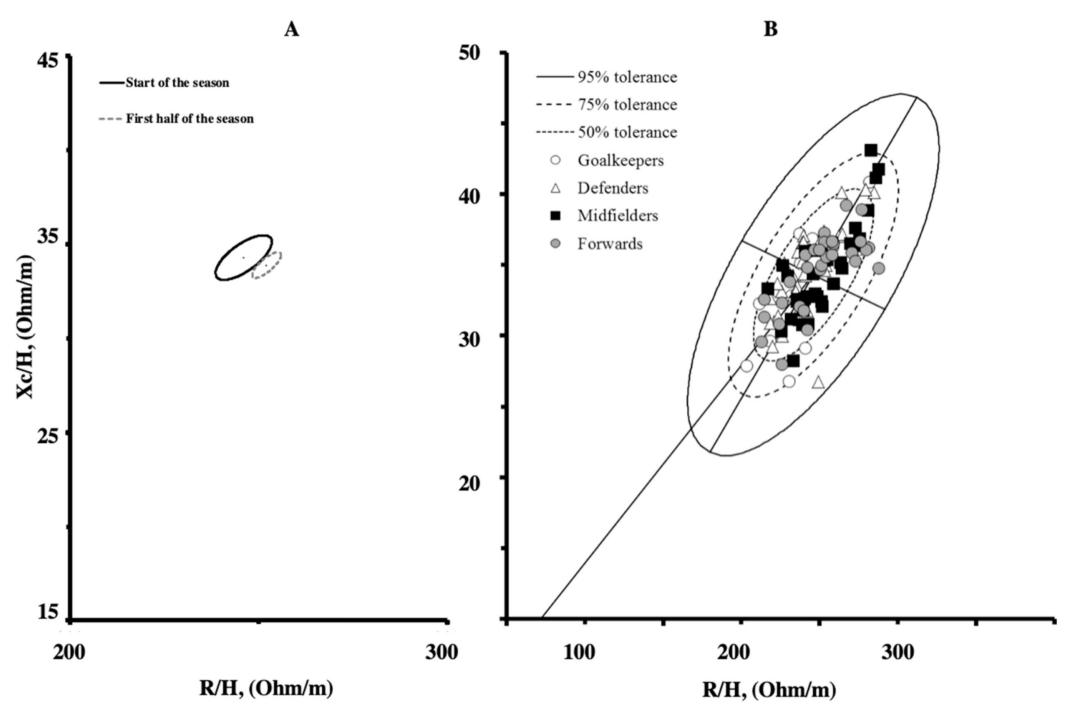

Figure 1. Mean impedance vectors with the $95 \%$ confidence ellipses for the soccer players measured at the start and at the first half of the competitive season [10] (Panel A). Scattergrams of the individual impedance vectors plotted on the new tolerance ellipses (Panel B).

\section{Discussion}

The aim of this study was to show the importance of evaluating bioelectric properties using BIVA references that are suitable for the competitive period in which the assessment is carried out. The results of this study, which provide bioelectrical impedance data for 131 elite players, showed how the tolerance ellipses created on the basis of measurements during the different phases of the competition differ significantly for elite soccer players.

The bioimpedance data reported in the present study are comparable to previous values reported during the start-of-the season period in elite soccer players [20-22]. In comparison with the elite Italian male soccer population investigated by Levi Micheli et al. [14], the elite soccer players measured in this study showed a significant vector shift to the left on the minor axis of the tolerance ellipses. This could indicate a greater cell mass, which is a consequence of the effects sought in the preparation phase (training and controlled diet) typically, designed to increase endurance level and increase strength [23]. In fact, in a previous study, Mascherini et al. [17] suggested that the shortening of the vector was associated with changes in hydration status and increases in body cell mass. In this study, the preparation phase could have increased the intracellular/extracellular water (ICW/ECW) ratio as can be seen from a higher PhA than that measured by Levi Micheli et al. [14] $\left(8.0 \pm 0.5^{\circ}\right.$ vs. $\left.7.7 \pm 0.6^{\circ}\right)$. Indeed, PhA is positively associated with the ICW/ECW ratio in athletes $[18,24]$. Bioelectric data reflect the content of body fluids and the cellular health of the athlete and during the season, which change in response to training load and physical condition over the season [25]. In fact, the new tolerance ellipses proposed in this study differ significantly from those generated in the study by Levi Micheli et al. [14], in which bioimpedance measurements were collected in the first half of the competitive period. Furthermore, Micheli Levi et al. [14] reported that BIA data was collected over 5 months, from October to January 2009-2010, a period of time that may have generated vector changes in the athletes themselves. Our hypothesis is that the increase in workload (training) and official matches from August to October (about 6-8 matches played) or from August to January (16-17 matches played) could lead to fatigue and increased muscle turnover, as well as reduced muscle function which could result in a shift to the right of the biompedance vector. In fact, during the season, the reduction of the PhA could indicate a decreased muscle function as shown by Norman et al. [26] However, since we have not performed any muscle function tests, this hypothesis will have to be further investigated in future studies. 
The reference ellipses proposed in the literature for athletes are population-specific. In addition to those for soccer players proposed by Levi Micheli [14], Campa and Toselli [15] measured male volleyball players in the second half of the in-season and showed specific BIA vector distribution in elite players in comparison to lower levels athletes. Subsequently, Giorgi et al. [16] provided bioelectrical impedance data of male road cyclists of varying performance levels, measured at the time of their optimal performance level and identified the 50, 75 and 95\% tolerance ellipses for the road cyclists population, as well as for the high-performance road cyclists. In addition to these, there are also ellipses for healthy athletes built on more than 1000 male and 440 female athletes during the off-season period, therefore suitable for evaluating BIVA in the first phase of the competitive season [12].

The authors are also aware of the limitations of the study. Firstly, the subjects come from the same territory; therefore, the results obtained are not generalizable to all the soccer players around the world: a larger sample size is required even in different countries. The second is that no division by ethnicity of the players has been made in order to obtain a sample as large as possible: currently an international data collection is active that will allow us to investigate both these two limitations.

A strength of this study is in the specific time period in which the measurements were collected, not only in regard to the competitive level of the athletes, but above all for the time span in which BIA assessments were performed. In fact, BIA measurements were collected within a week, just before the start of the season, a period of time too short to generate vector changes between the players.

For the reasons mentioned above, future studies conducted with the aim of providing BIVA references for athletes should carry out the measurements according to the competitive phase for which they want to provide the new references. This is very significative given that vector changes occur during the different phases of the season in athletes, and bioelectrical values must be as informative and specific as possible, in order to obtain accurate monitoring of the body composition and physical condition of the athlete. This study demonstrates the importance of evaluating athletes on period-specific BIVA references, providing new tolerance ellipses for assessing body composition and cellular health before the start of the competitive season in elite soccer players.

\section{Conclusions}

Through BIVA, it is possible to evaluate body composition and the state of physical condition in the different phases of the competition in elite soccer players. This study provides specific BIVA references for the start of the season period, through which the physical condition achieved after the preparation micro cycle in soccer can be assessed.

Author Contributions: Conceptualization, F.C. and G.M.; methodology, T.B.; software, F.C.; validation, F.M.I., G.P.; formal analysis, F.C.; investigation, T.B.; data curation, F.G.; writing-original draft preparation, F.C. and G.M.; supervision, A.T. and M.V.; project administration, G.A. All authors have read and agreed to the published version of the manuscript.

Funding: This research received no external funding.

Acknowledgments: The authors are grateful to all the soccer players who took part in this study.

Conflicts of Interest: The authors declare no conflict of interest.

\section{References}

1. Bongiovanni, T.; Trecroci, A.; Cavaggioni, L.; Rossi, A.; Perri, E.; Pasta, G.; Iaia, F.M.; Alberti, G. Importance of anthropometric features to predict physical performance in elite youth soccer: A machine learning approach. Res. Sports Med. 2020, 1-12. [CrossRef] [PubMed]

2. Campa, F.; Semprini, G.; Júdice, P.B.; Messina, G.; Toselli, S. Anthropometry, Physical and Movement Features, and Repeated-sprint Ability in Soccer Players. Int. J. Sports Med. 2019, 40, 100-109. [CrossRef] [PubMed]

3. Ackland, T.R.; Lohman, T.G.; Sundgot-Borgen, J.; Maughan, R.J.; Meyer, N.L.; Stewart, A.D.; Müller, W. Current status of body composition assessment in sport: Review and position statement on behalf of the ad hoc research working group on body composition health and performance, under the auspices of the I.O.C. Medical Commission. Sports Med. 2012, 42, 227-249. [CrossRef] [PubMed] 
4. Nattiv, A.; Loucks, A.B.; Manore, M.M.; Sanborn, C.F.; Sundgot-Borgen, J.; Warren, M.P.; American College of Sports Medicine. American College of Sports Medicine position stand. The female athlete triad. Med. Sci. Sports Exerc. 2007, 39, 1867-1882. [CrossRef]

5. Galanti, G.; Bocci, M.; Petri, C.; Tempesti, G.; Mascherini, G. Body composition analysis as a health index in cyclists. Med. Dello Sport 2018, 71,75-85. [CrossRef]

6. Mascherini, G.; Cattozzo, A.; Petri, C.; Francini, L.; Galanti, G. Application of Bioelectrical Vector Analysis in Professional Soccer Players: BIVA in sport. In Proceedings of the 2nd International Congress on Sports Sciences Research and Technology Support (icSPORTS-2014), Rome, Italy, 24-26 October 2014; Science and Technology Publications: Setúbal, Portugal; pp. 84-88. [CrossRef]

7. Castizo-Olier, J.; Irurtia, A.; Jemni, M.; Carrasco-Marginet, M.; Fernández-García, R.; Rodríguez, F.A. Bioelectrical impedance vector analysis (BIVA) in sport and exercise: Systematic review and future perspectives. PLoS ONE 2018, 13, e0197957. [CrossRef]

8. dos Santos, L.; Ribeiro, A.S.; Gobbo, L.A.; Nunes, J.P.; Cunha, P.M.; Campa, F.; Toselli, S.; Schoenfeld, B.J.; Sardinha, L.B.; Cyrino, E.S. Effects of Resistance Training with Different Pyramid Systems on Bioimpedance Vector Patterns, Body Composition, and Cellular Health in Older Women: A Randomized Controlled Trial. Sustainability 2020, 12, 6658. [CrossRef]

9. Toselli, S.; Badicu, G.; Bragonzoni, L.; Spiga, F.; Mazzuca, P.; Campa, F. Comparison of the effect of different resistance training frequencies on phase angle and handgrip strength in obese women: A randomized controlled trial. Int. J. Environ. Res. Public Health 2020, 17, 1163. [CrossRef]

10. Lukaski, H.C.; Piccoli, A. Bioelectrical Impedance Vector Analysis for Assessment of Hydration in Physiological States and Clinical Conditions. In Handbook of Anthropometry; Preedy, V., Ed.; Springer: Berlin/Heidelberg, Germany, 2012; pp. 287-305.

11. Campa, F.; Gatterer, H.; Lukaski, H.; Toselli, S. Stabilizing bioimpedance-vector-analysis measures with a 10-min cold shower after running exercise to enable assessment of body hydration. Int. J. Sports Physiol. Perform. 2019, 14, 1006-1009. [CrossRef]

12. Campa, F.; Matias, C.; Gatterer, H.; Toselli, S.; Koury, J.C.; Andreoli, A.; Melchiorri, G.; Sardinha, L.B.; Silva, A.M. Classic bioelectrical impedance vector reference values for assessing body composition in male and female athletes. Int. J. Environ. Res. Public Health 2019, 16, 5066. [CrossRef]

13. Koury, J.C.; Trugo, M.F.N.; Torres, A.G. Phase angle and bioelectrical impedance vectors in adolescent and adult male athletes. Int. J. Sports Physiol. Perform. 2014, 9, 798-804. [CrossRef] [PubMed]

14. Levi Micheli, M.; Pagani, L.; Marella, M.; Gulisano, M.; Piccoli, A.; Angelini, F.; Burtscher, M.; Gatterer, H. Bioimpedance and impedance vector patterns as predictors of league level in male soccer players. Int. J. Sports Physiol. Perform. 2014, 9, 532-539. [CrossRef] [PubMed]

15. Campa, F.; Toselli, S. Bioimpedance vector analysis of elite, subelite, and low-level male volleyball players. Int. J. Sports Physiol. Perform. 2018, 13, 1250-1253. [CrossRef]

16. Giorgi, A.; Vicini, M.; Pollastri, L.; Lombardi, E.; Magni, E.; Andreazzoli, A.; Orsini, M.; Bonifazi, M.; Lukaski, H.; Gatterer, H. Bioimpedance patterns and bioelectrical impedance vector analysis (BIVA) of road cyclists. J. Sports Sci. 2018, 36, 2608-2613. [CrossRef] [PubMed]

17. Mascherini, G.; Gatterer, H.; Lukaski, H.; Burtscher, M.; Galanti, G. Changes in hydration, body-cell mass and endurance performance of professional soccer players through a competitive season. J. Sports Med. Phys. Fit. 2015, 55, 749-755.

18. Campa, F.; Matias, C.N.; Marini, E.; Heymsfield, S.B.; Toselli, S.; Sardinha, L.B.; Silva, A.M. Identifying athlete body-fluid changes during a competitive season with bioelectrical impedance vector analysis. Int. J. Sports Physiol. Perform. 2020, 15, 361-367. [CrossRef]

19. Piccoli, A.; Pastori, G. BIVA Software; Department of Medical and Surgical Sciences, University of Padova: Padova, Italy, 2002.

20. Mascherini, G.; Castizo-Olier, J.; Irurtia, A.; Petri, C.; Galanti, G. Differences between the sexes in athletes' body composition and lower limb bioimpedance values. Muscles Ligaments Tendons J. 2018, 7, 573-581.

21. Mascherini, G.; Petri, C.; Galanti, G. Integrated total body composition and localized fat-free mass assessment. Sport Sci. Health 2015, 11, 217-225. [CrossRef]

22. Petri, C.; Mascherini, G.; Bini, V.; Anania, G.; Calà, P.; Toncelli, L.; Galanti, G. Integrated total body composition versus Body Mass Index in young athletes. Minerva Pediatr. 2020, 72, 163-169. [CrossRef] 
23. Gregson, W.; Littlewood, M. Science in Soccer. In Translating Theory into Practice; Bloomsburry Publishing Plc: London, UK, 2018.

24. Marini, E.; Campa, F.; Buffa, R.; Stagi, S.; Matias, C.N.; Toselli, S.; Sardinha, L.B.; Silva, A.M. Phase angle and bioelectrical impedance vector analysis in the evaluation of body composition in athletes. Clin. Nutr. 2020, 39, 447-454. [CrossRef]

25. Reis, J.F.; Matias, C.N.; Campa, F.; Morgado, J.P.; Franco, P.; Quaresma, P.; Almeida, N.; Curto, D.; Toselli, S.; Monteiro, C.P. Bioimpedance Vector Patterns Changes in Response to Swimming Training: An Ecological Approach. Int. J. Environ. Res. Public Health 2020, 17, 4851. [CrossRef] [PubMed]

26. Norman, K.; Stobäus, N.; Pirlich, M.; Bosy-Westphal, A. Bioelectrical phase angle and impedance vector analysis-Clinical relevance and applicability of impedance parameters. Clin. Nutr. 2012, 31, 854-861. [CrossRef] [PubMed]

Publisher's Note: MDPI stays neutral with regard to jurisdictional claims in published maps and institutional affiliations.

(C) 2020 by the authors. Licensee MDPI, Basel, Switzerland. This article is an open access article distributed under the terms and conditions of the Creative Commons Attribution (CC BY) license (http://creativecommons.org/licenses/by/4.0/). 